\title{
Exploring Coupling Relationship between Urban Connection and High-quality Development Using the Case of Lanzhou-Xining Urban Agglomeration
}

\author{
Junfeng Yin $\mathbb{D}^{1},{ }^{1}$ Haimeng Liu $\mathbb{D},{ }^{2}$ Peiji Shi, ${ }^{1}$ and Weiping Zhang ${ }^{1}$ \\ ${ }^{1}$ College of Geography and Environmental Science, Northwest Normal University, Lanzhou 730070, China \\ ${ }^{2}$ Institute of Geographical Sciences and Natural Resources Research, Chinese Academy of Sciences, Beijing 100101, China \\ Correspondence should be addressed to Haimeng Liu; liuhm@igsnrr.ac.cn
}

Received 27 August 2021; Revised 12 October 2021; Accepted 21 October 2021; Published 3 November 2021

Academic Editor: Ning Cai

Copyright (C) 2021 Junfeng Yin et al. This is an open access article distributed under the Creative Commons Attribution License, which permits unrestricted use, distribution, and reproduction in any medium, provided the original work is properly cited.

\begin{abstract}
Based on socioeconomic statistical data, transport data, and network big data, the urban connection index (UCI) was constructed in terms of industry, transportation, information, and innovation, and the high-quality development index (HDI) was established from five aspects: innovation, coordination, green development, openness, and sharing. Taking Lanzhou-Xining urban agglomeration as a case, the urban connection intensity and high-quality development level were measured to analyze the relationship between them. From 2012 to 2018, the UCI and HDI of each city showed different degrees of growth. Note that there exist significant regional differences, with Lanzhou and Xining having the largest difference. The biggest gap among cities lies in the innovative connection intensity. Moreover, urban external connections are closely related to high-quality development, especially innovation and green development. For every $1 \%$ increase in industrial and transport connection, the HDI will increase by $0.317 \%$ and $0.159 \%$, respectively. This study provides a methodological reference for measuring urban connectivity and provides decision support for high-quality development in China and other countries.
\end{abstract}

\section{Introduction}

An urban system is characterized by openness, nonlinearity, diversity, fluctuation, and self-organization $[1,2]$. The openness is directly revealed by the continuous exchange of matter, energy, and information between different cities. This external connection allows the urban system to constantly replenish energy, which is one of the main driving forces to keep its vitality and orderliness $[3,4]$. In urban agglomerations, cities are particularly interconnected [5], and the closeness between cities is an important indicator in reflecting the development degree of urban agglomerations. In 2017, China proposed the concept of high-quality development, aiming to transform from seeking "growth" to seeking "better growth" with general improvement in socioeconomic development. High-quality development will be the theme of China's socioeconomic development in the 14th Five-Year Plan (2021-2025) and beyond. Following the high-quality development path means staying committed to the people-oriented approach and the concept of innovative, coordinated, green, open, and shared development [6]. Currently, urban agglomerations in China comprise $75 \%$ of the population and $80 \%$ of the gross domestic product (GDP), being major spatial carriers of socioeconomic development [7]. Therefore, it is necessary to explore the relationship between urban connection intensity and highquality development level in typical urban agglomerations for regional sustainable development $[8,9]$.

How to measure urban connection intensity and highquality development level? What is the relationship between these two systems? Existing studies have mainly focused on the quantitative measurement of urban networks and connections. Different sources of flows were used to reflect the functional linkages of cities, such as migration [10], transport [11, 12], trade [13], and information [14]. The POLYNET project measured the degree of cohesion of urban 
agglomerations in Europe by analyzing daily commuting flows [15]. The intensity, direction, network pattern, and hierarchical structure of the connections between cities have been discussed [16-19]. The measurement methods of urban connection intensity mainly include the gravity model $[20,21]$, urban flow intensity model [22], regional accessibility [23], and social network analysis [24, 25]. However, most studies focused only on one dimension of urban connections, lacking comprehensive analysis. In addition, the concept of high-quality development proposed by the Chinese government has only gained attention recently. High-quality development in the new era is expected to coordinate the relationship between speed and quality of development [26]. That is, total factor productivity needs to be increased and old growth drivers should be replaced [27]. Long et al. evaluated the high-quality development of the Yellow River basin from five aspects of society, economy, resources, ecology, and culture [28]. Although the influence of foreign direct investment characteristics on China's highquality economic development has been studied [29], there is no consensus on the understanding and measurement of urban high-quality development.

Considering the shortcomings of current research, the urban connection index (UCI) and high-quality development index (HDI) were constructed based on the complexity theory. Taking Lanzhou-Xining urban agglomeration as a case, the connection intensity and high-quality development level of each city from 2012 to 2018 were evaluated. Then, we explained quantitatively and qualitatively the coupling and coordination relationship between UCI and HDI. Finally, the popularization significance and policy implications were discussed. This study provides a methodological reference for measuring urban connectivity and provides decision support for high-quality development in China and other countries.

\section{Theoretical Basis}

A city is a complex system like an organism, and its inflow and outflow of matter, energy, and information are metabolisms [30-32]. Complexity science believes that the openness of a system and the fluidity of internal system elements are the driving forces for the vitality and continuous evolution of all complex systems on the Earth: a basic law of nature [33]. Similarly, as an open complex organic regional system, the city also obeys this law. There is an uninterrupted material, people, energy, and information flow within a city or between different cities [34]. The various "flows" between cities are driven by active and passive forces, forming intricate network connections between cities. The key to assessing a city's metabolic vitality is to quantify the intensity of these flows. The stronger the interaction between cities is, the higher the socioeconomic output of the cities is [35]. Especially, in the Information Age characterized by a new network society and informational cities, this interaction is becoming more significant for urban development [36].

A two-way positive and negative feedback effect occurs between UCI and HDI (Figure 1). The strengthened external connections of the urban system promote and support the

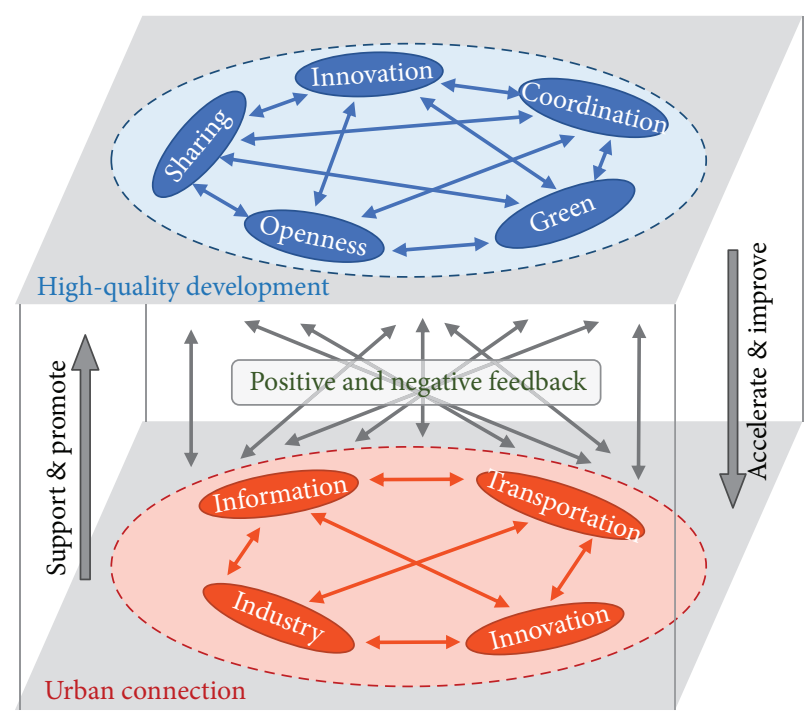

FIGURE 1: Relationship between urban connection and high-quality development.

high-quality development of a city. The urban high-quality development will in turn promote the openness of the city. At the city scale, the higher the openness of a city system is, the higher the mobility of various elements within the city is and the higher the livability and sustainability of the city are [37]. At the urban agglomeration scale, the higher the connections between cities in terms of industry, transport, information, and innovation are, the stronger the vitality and competitiveness of the urban agglomeration and the cities within it are and the greater the high-quality development of the region will be. Thus, we believe cities' external connections may be related to their high-quality development. Quantitative verification will be performed below.

\section{Methodology and Data}

3.1. Study Area. The Lanzhou-Xining urban agglomeration is one of the 19 important urban agglomerations proposed in the 13th Five-Year Plan of China (2016-2020). It is a typical urban agglomeration in the initial development stage in central and western China, and the Chinese government aims to build a growth pole to support the regional development. Located at the intersection of three natural regions in China, the eastern monsoon region, arid, and semiarid region, Qinghai-Tibet Plateau is an important transportation hub and economic channel connecting the central and western China with eastern China with numerous trunk railways and national highways (Figure 2). It covers an area of $9.75 \times 10^{4} \mathrm{~km}^{2}$. The total population was 11.94 million, and the urbanization rate was $49.79 \%$ by 2019 . The GDP in 2019 was about 577.18 billion yuan, accounting for $49.40 \%$ of the sum of Gansu and Qinghai province.

3.2. Urban Connection Intensity Measurement. The flow of people, matter, and energy is mainly realized through industrial and traffic links between cities and the flow of information through the Internet, telecommunication 


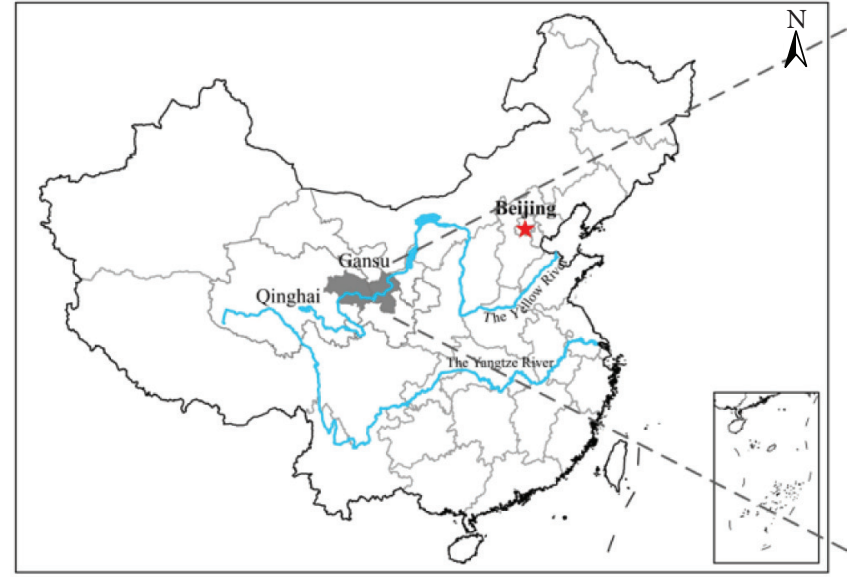

Study region

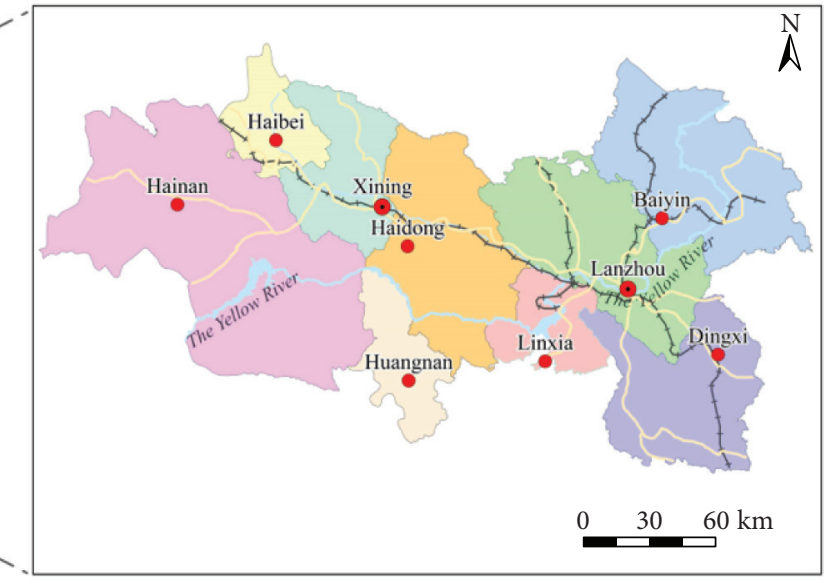

- City $\quad \longrightarrow$ Main railway
Provincial capital
Main highway

Figure 2: Lanzhou-Xining urban agglomeration.

networks, and other channels [38, 39]. Each city is one node in a complex network formed by various "flows" between cities [40]. Therefore, we chose four dimensions of industry, transportation, information, and innovation to comprehensively measure the external connection intensity of a city.

3.2.1. Industrial Connection Intensity. It is calculated based on the industrial influence coefficient and induction coefficient [41]. Influence coefficient refers to the amount of output that needs to be increased by other industrial sectors after one unit of the final product is added [42]. The formula is as follows:

$$
T t_{j}=\frac{\sum_{i=1}^{n} b_{i j}}{(1 / n) \sum_{i=1}^{n} \sum_{j=1}^{n} b_{i j}}, \quad i, j=1,2,3, \ldots, n,
$$

where $T t_{j}$ represents the influence coefficient of $j$ industrial sector, $b_{i j}$ is the coefficient of the $i$ th row and $j$ th column in the Leontief inverse matrix, and $n$ is the number of industries: $\sum_{i=1}^{n} b_{i j}$ is the sum of the $j$ th column of the matrix and is the average of the sum of the columns of the matrix.

Induction coefficient refers to the amount of output required by a certain sector to meet the production demand of all sectors after each sector in the region adds one unit of the final product [43]. The formula is as follows:

$$
S t_{i}=\frac{\sum_{j=1}^{n} b_{i j}}{(1 / n) \sum_{i=1}^{n} \sum_{j=1}^{n} b_{i j}}, \quad i, j=1,2,3, \ldots, n,
$$

where $S t_{i}$ represents the induction coefficient of the sector $i$ affected by other industrial sectors. $\sum_{j=1}^{n} b_{i j}$ is the sum of the $i$ th row of the matrix.

Drawing on previous studies [44, 45], we established industrial connection intensity based on "spatial connection" and "influence." The industrial connection intensity is expressed by actual connection, which is related to the industrial scale. The formula is as follows:

$$
\begin{aligned}
C i_{k} & =\sum_{i=1}^{18} S t_{i} T t_{i} S c_{i} a_{m}, \\
C i_{k 1-k 2} & =\frac{\sqrt{C_{i k 1} C_{i k 2}}}{D_{k 1-k 2}} \\
E_{p-I C} & =\sum_{i=1}^{m} C i_{k 1-k 2},
\end{aligned}
$$

where $C i_{k}$ represents the industrial connection intensity of $n$ industries of city $k$ and its value can reflect the external radiation capacity of the city's industrial development, $S c_{i}$ represents the scale of employment in each industry, $a_{m}$ represents the weight of each industry $i$ obtained by the analytic hierarchy process (AHP), $C i_{k 1-k 2}$ indicates the intensity of industrial connections between cities $k_{1}$ and $k_{2}$, $D_{k 1-k 2}$ indicates the distance between two cities, calculated using the shortest expressway operating mileage between two cities, $E_{p-I C}$ indicates the total intensity of industrial connections in city $p$, and $m$ is the number of cities in the urban agglomeration.

3.2.2. Transportation Connection Intensity. The intensity of intercity transportation connection determines the connection degree of people, matter, and other flows [46]. Considering the density of train connections in LanzhouXining urban agglomeration is low and many cities still rely on low-grade highways, the number of passenger buses running between cities is added into the model. The formula is as follows:

$$
\begin{aligned}
& T_{p q}=a G_{p q}+b D_{p q}+c K_{p q}+d B_{p q}, \\
& E_{p q}=\frac{T_{p q}+T_{q p}}{2},
\end{aligned}
$$




$$
E_{p-T C}=\sum_{q=1}^{m} E_{p q},
$$

where $G_{p q}, D_{p q}, K_{p q}$, and $B_{p q}$, respectively, indicate the daily number of G-series high-speed railway, D-series high-speed railway, ordinary railway, and passenger buses from city $p$ to city $q . a, b, c$, and $d$ represent the coefficients of G-series highspeed railway, D-series high-speed railway, ordinary railway, and passenger buses. To scientifically quantify the connection intensity of different vehicles, the weight according to the speed of various vehicles was calculated. Taking the speed of G-series high-speed rail (speed of $300 \mathrm{~km} / \mathrm{h}$ ) as the benchmark, $a$ is taken as 1 , correspondingly $b$ is $250 / 300=5 / 6, c$ is $120 / 300=2 / 5$, and $d$ is $80 / 300=4 / 15$. $T_{p q}$ represents the transportation connection intensity from city $p$ to city $q ; E_{p q}$ represents the average value of transportation connection between city $p$ and city $q ; E_{p-T C}$ represents the total intensity of transportation connections in city $p$.

3.2.3. Information Connection Intensity. Using Baidu search index [47], we collected the number of searches for each other between the two cities from 2012 to 2018 in Lanzhou-Xining urban agglomeration. The spatial matrix of the Baidu search index for two cities was constructed, and then, the total amount of information connections is calculated by [48]

$$
E_{p-N C}=\sum_{q=1}^{m} P_{q} \times Q_{p},
$$

where $P_{q}$ represents the number of searches of city $p$ to city $q$, $Q_{p}$ represents the number of searches of city $q$ to city $p$, and $E_{p-N C}$ indicates the information connection intensity of city $p$.

3.2.4. Innovative Connection Intensity. Using the Web of Science database, we adopted centrality to reflect the position of cities in the knowledge innovation network of the urban agglomeration [49]. We searched for the co-authored published papers between cities in the database during the research period. The formula is as follows:

$$
E_{p-I N C}=\sum_{q=1}^{m} \text { Citypair }_{q p},
$$

where Citypair $q p$ represents the number of co-published papers between city $p$ and city $q$ and $E_{p-I N C}$ represents the innovative connection intensity of city $p$.

3.2.5. UCI. We constructed the UCI based on the four indexes of $E_{p-I C}, E_{p-T C}, E_{p-N C}$, and $E_{p-I N C}$. Using AHP [50], the weight of industry, transportation, information, and innovation are set as $0.283,0.266,0.234$, and 0.217 , respectively. The formula of UCI is as follows:

$$
Z_{p-U C I}=\sum_{s=1}^{4} E_{p s} W_{s},
$$

where $Z_{p-U C I}$ represents the urban connection index of the $p$ th city, $E_{p s}$ represents the standardized value of the connection intensity of the sth index of the pth city, and $W_{s}$ represents the weight of the sth index.
3.3. A Comprehensive Index System for High-Quality Development. High-quality development is one of China's top priorities in the new era [51]. The evaluation system of urban high-quality development is based on China's new development concept, namely, "innovation, coordination, green, openness, and sharing," the core of which is to balance the speed and quality of development [52]. Drawing on previous studies [28], combined with data availability and representativeness, we constructed the comprehensive index system. The index weight was determined by expert consultation [53] and the entropy method [54], and then, the average of the two was calculated as the comprehensive weight (Table 1).

The HDI is calculated as follows:

$$
H D I=\sum_{j=1}^{m} W_{j} Y_{i j},
$$

where $Y_{i j}$ represents the standardized processing value of the $j$ th index in the $i$ th city, $W_{j}$ represents the weight of the $j$ th index, and $m$ is the number of indexes.

3.4. Coupling Degree and Coordination Degree. The concept of "coupling" refers to the interaction and mutual influence of two or more systems [34]. We used the coupling degree and coordination degree to explore the possible relationship between UCI and HDI. The formula is as follows:

$$
C=\sqrt{\frac{u_{1} \times u_{2}}{\left(u_{1}+u_{2}\right)^{2}}},
$$

where $C$ represents the coupling degree, $u_{1}$ represents the $\mathrm{UCI}$, and $u_{2}$ is the HDI. The formula of coordination degree is as follows:

$$
\begin{aligned}
& D=\sqrt{C \times T}, \\
& T=\alpha u_{1}+\beta u_{2},
\end{aligned}
$$

where $D$ represents the coordination degree, $T$ represents the comprehensive evaluation index of the two systems, and $\alpha$ and $\beta$ represent the undetermined coefficient (we assumed that the two systems are equally important; both $\alpha$ and $\beta$ were assigned 1/2). Referring to previous research [55], the coupling degree and coordination degree were classified, as listed in Table 2.

3.5. Data Sources. The socioeconomic data were derived from The Statistical Yearbook of Chinese Cities, Statistical Yearbook of Gansu and Qinghai Province, Industry Classification of National Economy (GB/T 4754-2017), and statistical yearbook of each city. The railway traffic data were obtained from the Ministry of Transport (https://www.mot. gov.cn/), the National Railway Administration (http://www. nra.gov.cn/), and the website of China Railway 12306 (https://www.12306.cn). Highway traffic operation data were obtained from The Atlas of China's Expressways and Urban and Rural Roads and the official websites (http://jtys.gansu. gov.cn/ and http://jtyst.qinghai.gov.cn/). Passenger 
TABLE 1: Evaluation system of urban high-quality development.

\begin{tabular}{|c|c|c|c|c|c|c|}
\hline Goal layer & Criterion layer & Weight & Indexes & $\begin{array}{c}\text { Index } \\
\text { mark }\end{array}$ & $\begin{array}{c}\text { Index } \\
\text { attributes }\end{array}$ & $\begin{array}{c}\text { Comprehensive } \\
\text { weight }\end{array}$ \\
\hline \multirow{15}{*}{$\begin{array}{l}\text { Urban high-quality } \\
\text { development index system }\end{array}$} & \multirow{3}{*}{$\begin{array}{l}\text { Innovation } \\
\text { development }\end{array}$} & \multirow{3}{*}{0.2} & $\begin{array}{l}\text { Number of patent applications per } \\
10,000 \text { people }\end{array}$ & A1 & + & 0.072 \\
\hline & & & $\begin{array}{l}\mathrm{R} \& \mathrm{D} \text { internal expenditure as a } \\
\text { percentage of GDP }\end{array}$ & A2 & + & 0.059 \\
\hline & & & R\&D personnel per 10,000 people & A3 & + & 0.069 \\
\hline & \multirow{3}{*}{$\begin{array}{l}\text { Coordination } \\
\text { development }\end{array}$} & \multirow{3}{*}{0.2} & Urban-rural income ratio & $\mathrm{B} 1$ & - & 0.058 \\
\hline & & & GDP per capita & $\mathrm{B} 2$ & + & 0.063 \\
\hline & & & $\begin{array}{l}\text { The proportion of urban } \\
\text { population in total population }\end{array}$ & $\mathrm{B} 3$ & + & 0.079 \\
\hline & \multirow{3}{*}{ Green development } & \multirow{3}{*}{0.2} & $\mathrm{PM}_{2.5}$ concentration & $\mathrm{C} 1$ & - & 0.069 \\
\hline & & & $\begin{array}{l}\text { Green coverage rate in built-up } \\
\text { area }\end{array}$ & $\mathrm{C} 2$ & + & 0.072 \\
\hline & & & $\begin{array}{c}\text { Energy consumption per unit of } \\
\text { GDP }\end{array}$ & C3 & - & 0.059 \\
\hline & \multirow{3}{*}{$\begin{array}{c}\text { Openness } \\
\text { development }\end{array}$} & \multirow{3}{*}{0.2} & $\begin{array}{c}\text { The proportion of total import and } \\
\text { export in GDP }\end{array}$ & D1 & + & 0.070 \\
\hline & & & $\begin{array}{c}\text { Actual foreign investment as a } \\
\text { proportion of GDP }\end{array}$ & D2 & + & 0.068 \\
\hline & & & $\begin{array}{l}\text { Number of internet broadband } \\
\text { access users per } 10,000 \text { people }\end{array}$ & D3 & + & 0.062 \\
\hline & \multirow{3}{*}{$\begin{array}{c}\text { Sharing } \\
\text { development }\end{array}$} & \multirow{3}{*}{0.2} & $\begin{array}{l}\text { Number of beds in health } \\
\text { institutions per } 10,000 \text { people }\end{array}$ & E1 & + & 0.062 \\
\hline & & & $\begin{array}{l}\text { Public library collections per } \\
10,000 \text { people }\end{array}$ & E2 & + & 0.065 \\
\hline & & & Road area per capita & E3 & + & 0.073 \\
\hline
\end{tabular}

TABLE 2: The classification of coupling degree and coordination degree.

\begin{tabular}{|c|c|c|c|}
\hline Coupling & Coupling phase & Coordination & Coordination level \\
\hline $0.0<C \leq 0.3$ & Low coupling stage & $0.00 \leq D<0.19$ & Severe imbalance \\
\hline $0.3<C \leq 0.5$ & Antagonism stage & $0.20 \leq D<0.39$ & Mild disorder \\
\hline $0.5<C \leq 0.8$ & Run-in stage & $0.40 \leq D<0.59$ & General coordination \\
\hline \multirow[t]{2}{*}{$0.8<C \leq 1.0$} & Highly coupling stage & $0.60 \leq D<0.89$ & Well coordination \\
\hline & & $0.80 \leq D<1.00$ & Advanced coordination \\
\hline
\end{tabular}

frequencies were obtained from Qunar (https://www.qunar. $\mathrm{com} /$ ) and Ctrip (https://www.ctrip.com/). Data related to Baidu Search Index were from its official website (http:// index.baidu.com). The number of co-published papers was determined from the Web of Science database. $\mathrm{PM}_{2.5}$ concentration data were obtained from the Dalhousie University Atmospheric Composition Analysis Group.

\section{Results}

\subsection{UCI of Lanzhou-Xining Urban Agglomeration}

4.1.1. Industrial Connection Intensity. The intensity of industrial connections among cities in Lanzhou-Xining urban agglomeration has been rising, from an average of 226.08 in 2012 to 502.65 in 2018 (Figure 3(a)). The intensity of industrial connections among cities in the region varied greatly. Cities in the eastern part of the urban agglomeration (Lanzhou, Baiyin, Dingxi, and Linxia) were more closely connected with the external industry than cities in the western part (Xining, Haidong, Hainan, Haibei, and
Huangnan). The industrial connection intensities in Hainan, Haibei, and Huangnan were all below 200. During the study period, Lanzhou was the strongest and Hainan the weakest of the urban agglomeration in industrial connection intensity, and the gap between the two widens year by year.

4.1.2. Transportation Connection Intensity. Lanzhou has always had the largest total transportation connections in the urban agglomeration, which increased from 54.27 in 2012 to 132.20 in 2018 (Figure 3(b)). Lanzhou, Xining, and Dingxi are important transportation hubs, and the intensity of transportation connections between the three cities has always been at the top. However, the transportation connection of Huangnan and Haibei is relatively weak, and the growth is slow. In the urban agglomeration, only Lanzhou and Dingxi have G-series high-speed trains, and Lanzhou, Xining, and Dingxi have D-series high-speed trains. Generally, cities located along the main railway lines have the closest transportation connections. The peripheral cities are weakly connected with the core cities. 


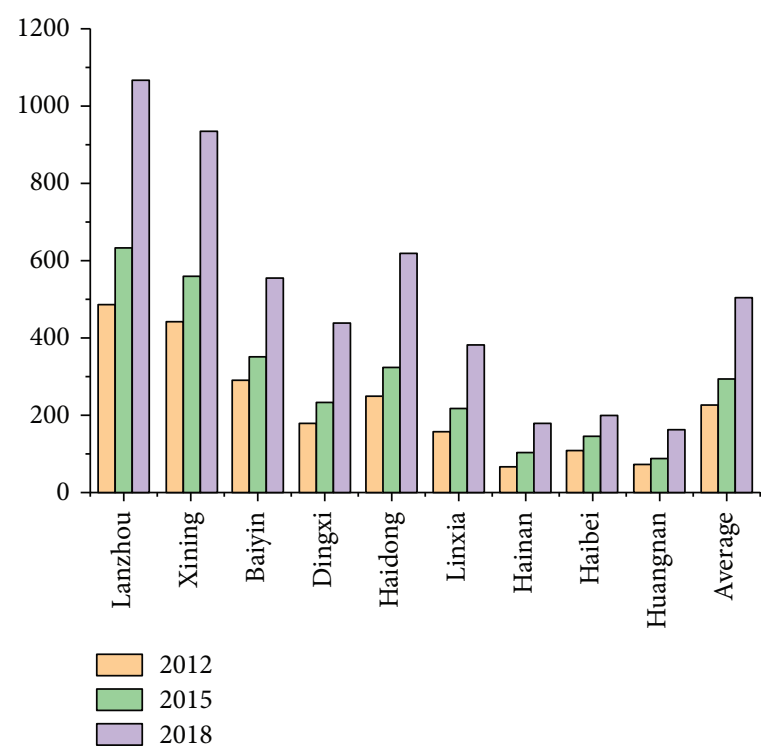

(a)

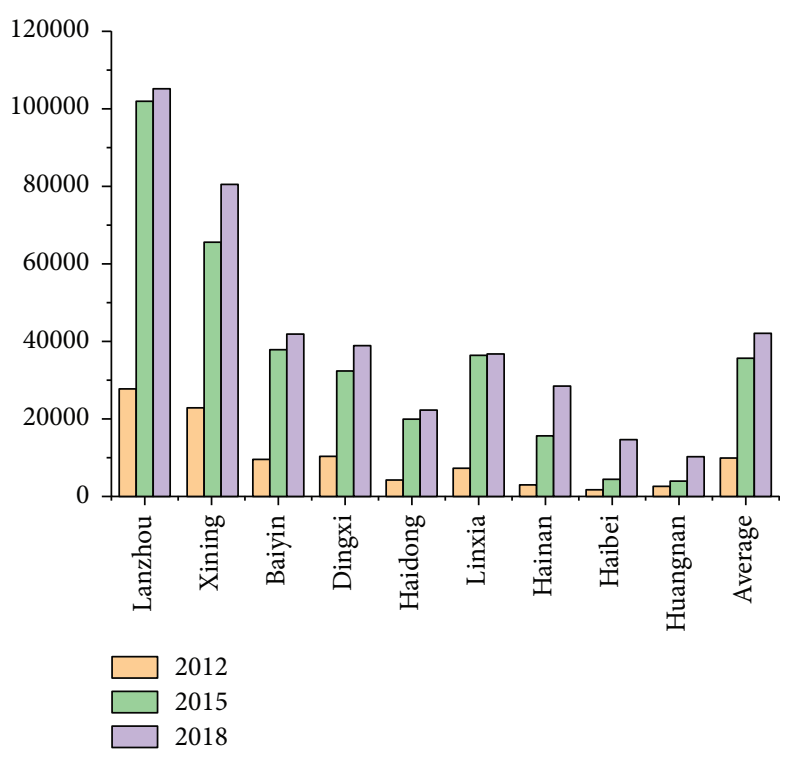

(c)

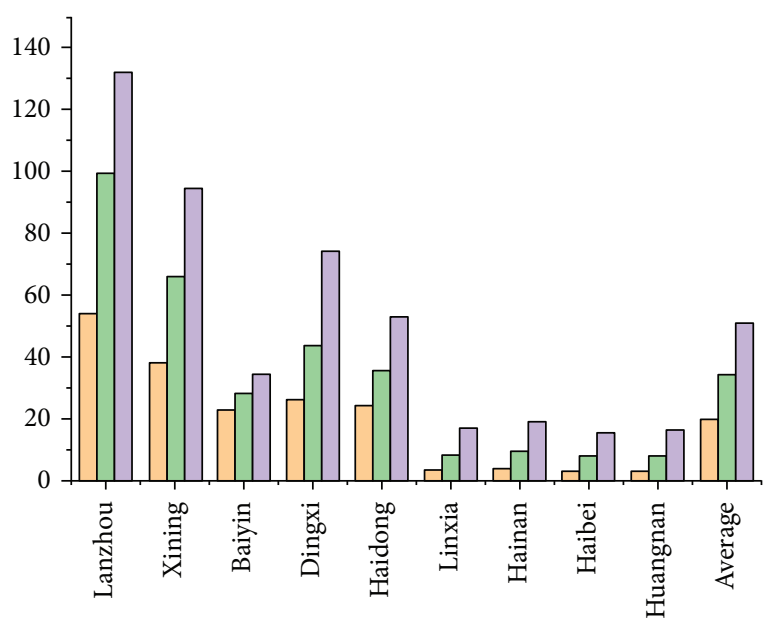

2012
2015
2018

(b)

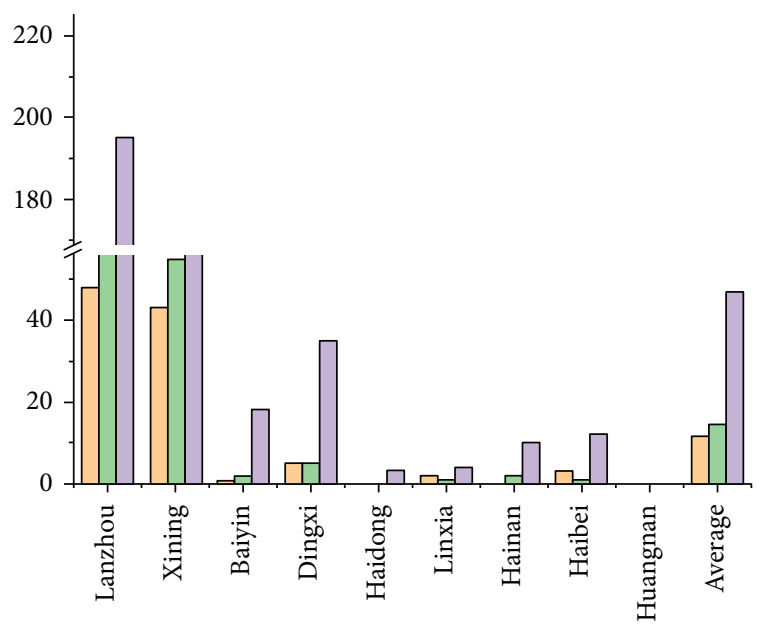

2012

2015

(d)

FIgURE 3: The four dimensions of urban connection indexes in Lanzhou-Xining urban agglomeration. (a) Industrial connection, (b) transportation connection, (c) information connection, and (d) innovative connection.

4.1.3. Information Connection Intensity. From 2012 to 2018, the information connection intensity of all cities in Lanzhou-Xining Urban agglomeration showed an increasing trend, but the rate of increase differed (Figure 3(c)). The intensity of information connection for Lanzhou and Xining has always been superior. The information connection intensity of Huangnan was the worst. Hainan's information links are growing at a rapid pace. Overall, the information connection intensity in Gansu province was much higher than that in Qinghai province.

4.1.4. Innovative Connection Intensity. The innovative connection intensity decreased from the core cities of the urban agglomeration such as Lanzhou and Xining to the surrounding cities, presenting a cliff-like decline; an obvious dual-center spatial structure was established (Figure 3(d)). Lanzhou and Xining have abundant higher education institutions and scientific research institutions, offering many high-level innovation platforms, which are conducive to the cities' innovative connections. The western region has poor conditions for scientific research and innovation, leading to the relatively low innovative connection intensity.

4.1.5. UCI. From 2012 to 2018, the UCI of each city in Lanzhou-Xining urban agglomeration showed an increasing trend, but the speed and amplitude of the rise differed. Cities with the fastest increase in the UCI were Huangnan and Hainan, with an average growth rate of over $6.60 \%$ and 
$1.21 \%$, respectively (Figure 4). The UCI of Lanzhou was 2.84 times that of the average of the urban agglomeration, indicating that Lanzhou is closely connected with other cities and plays a leading role in the urban agglomeration. Xining had the second-highest UCI, and the UCI of Huangnan has always been at the bottom. The radiation and driving effects of Lanzhou and Xining on the surrounding cities are becoming stronger. The average UCI has been steadily increasing, reflecting that the spatial connection within urban agglomeration is getting closer.

4.2. The High-Quality Development of Lanzhou-Xining Urban Agglomeration. There are obvious spatial differences in the HDI and four dimensions of all cities in the Lanzhou-Xining urban agglomeration (Figure 5). Lanzhou and Xining are significantly better than other cities in all dimensions. The innovation index of Lanzhou was about 5 times the average of the urban agglomeration. The gap in the green development index among cities was small, and Huangnan had the lowest score. For the dimension of openness development, the scores of Linxia, Hainan, Haibei, and Huangnan scored were lower than 0.01 , nearly five times lower than the highest value. The variation in the shared development index was markedly different from that in other dimensions, showing the spatial characteristics of "low in the middle and high on both sides."

At the time scale, the HDI of each city showed an upward trend during the study period, but the growth rates differed. Lanzhou has always been the first in terms of the HDI, whereas Linxia and Haibei have always been at the bottom. The highest HDI value was 4.6 times higher than the lowest HDI. The largest gap was in innovation development, and the smallest gap was seen in green development and shared development. The variation coefficient (VC) of the HDI reflects the degree of imbalance in spatial development in the urban agglomeration. Table 3 shows that the imbalance reduced from 2012 to 2018 , and the VC decreased from 0.847 to 0.697 . Overall, the HDI of the eastern cities in the urban agglomeration was higher than that of the western cities.

\subsection{Coupling Relationship between UCI and HDI}

4.3.1. Pearson Correlation Analysis. UCIs were significantly correlated with most indexes of high-quality development, especially innovation development and green development (Table 4), indicating that the enhanced connection of cities is likely to facilitate development. The urban connection was strongly correlated with the level of innovation development and green development. The three indexes of innovation development were significantly related to the three subsystems of urban connection; the proportion of actual use of foreign direct investment in GDP was only significantly related to industrial and information connection; the urban connection subsystem did not significantly correlate with the urban-rural income ratio and the number of books in public libraries per 10,000 people.

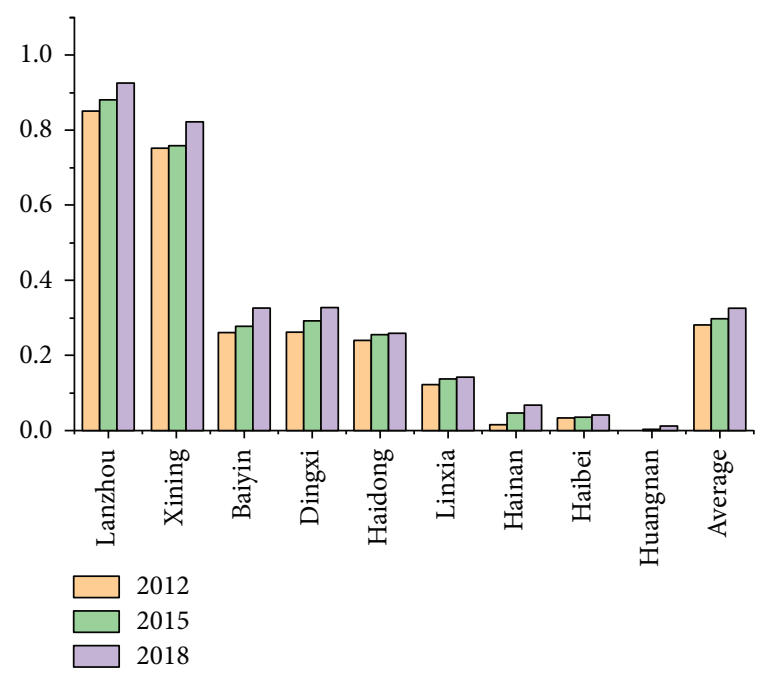

FIgURE 4: Urban connection index in Lanzhou-Xining urban agglomeration.

4.3.2. Panel Regression Analysis. Based on the panel data of UCI and HDI, combined with the data structure and the Hausman test results, we selected a random-effects regression model to test the relation between HDI and four UCIs. As shown in Table $5, \operatorname{lnIC}, \operatorname{lnTC}, \operatorname{lnNC}$, and $\operatorname{lnINC}$ represent the logarithmic form of industry, transportation, information, and innovation, respectively. The industrial and traffic connection had a significant positive impact on the HDI, while the information and innovative connection had no significant impact.

The elasticity coefficient between industrial connection and HDI was 0.317 , indicating that, for every $1 \%$ increase in the degree of industrial connection of a city, its high-quality development level increased by about $0.317 \%$. The elasticity coefficient of a city's external transportation connection and HDI was 0.159 , indicating that every $1 \%$ increase in a city's transportation connection increases its high-quality development level by $0.159 \%$. Increased transportation connections could accelerate the free flow of production factors such as population, logistics, and information between cities and increase in the openness and sharing of cities. The information connection and the innovation connection had no significant impact on the HDI, but the force was positive, indicating that an enhancement of the information and innovative connection may improve the urban high-quality development level to a certain extent.

4.3.3. Coupling Degree and Coordination Degree. The coupling degree of all cities showed an upward trend during 2012-2018 (Figure 6), but the magnitude of increase varied greatly. The coupling degree of Huangnan increased rapidly, from 0.071 in 2012 to 0.346 in 2018 , but it was still at the bottom. The coupling degree of other cities varied less, with values in the range of $0.37-0.49$, and maintained the same coupling stage during the study period. The coordination degree of Huangnan, Haibei, and Hainan was below 0.2, which represents a serious imbalance state; Lanzhou and 

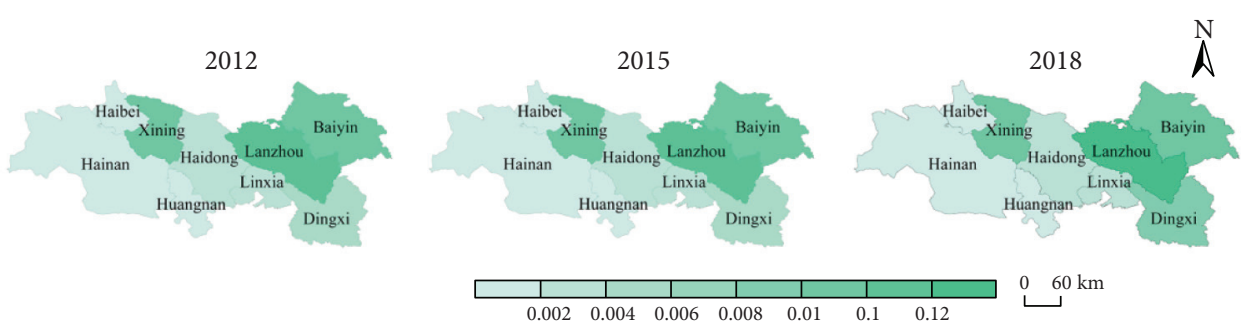

(a)
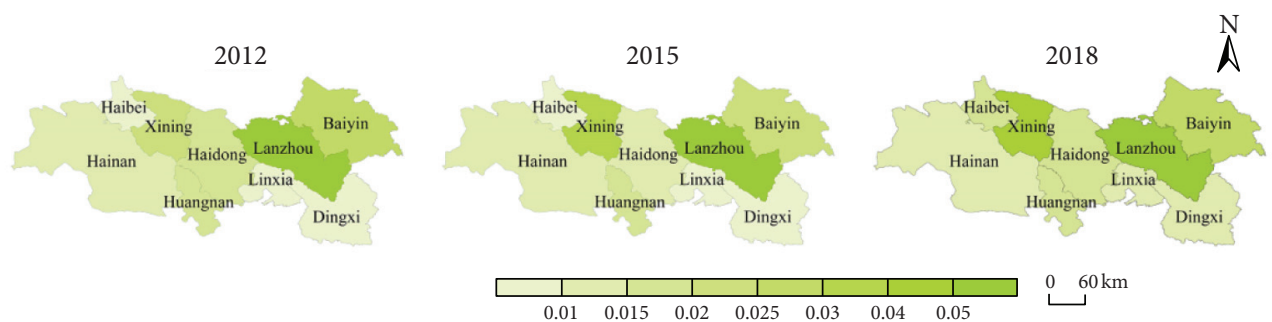

(b)
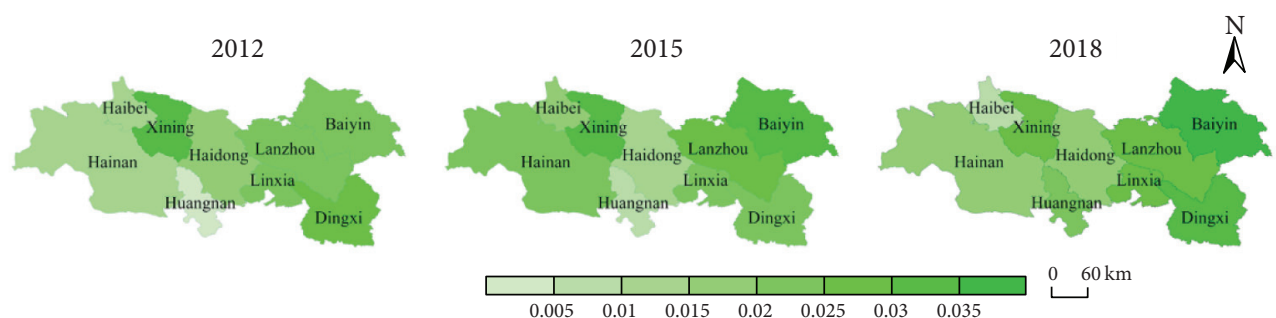

(c)
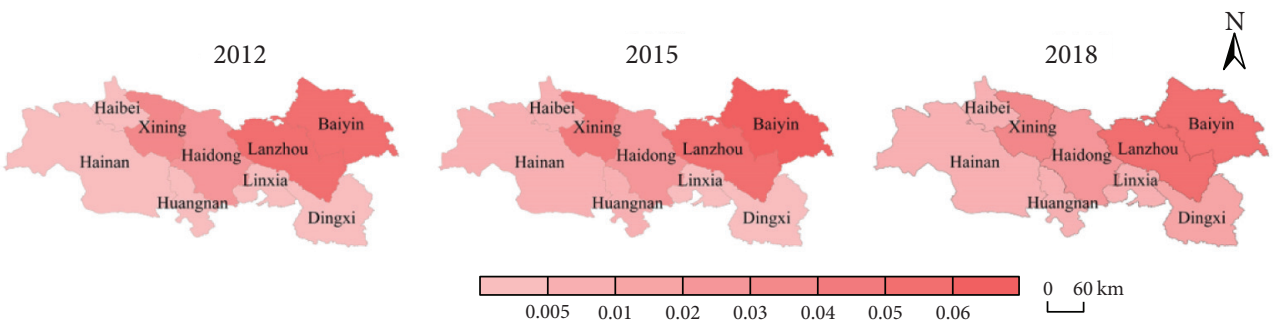

(d)
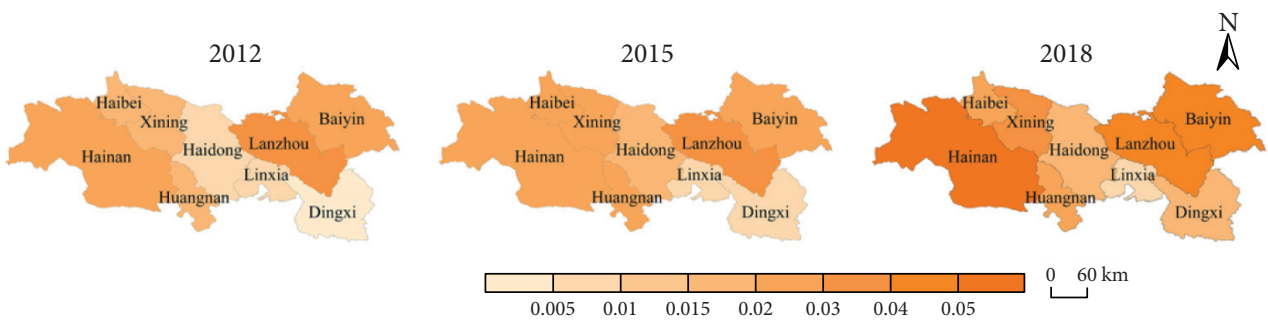

(e)
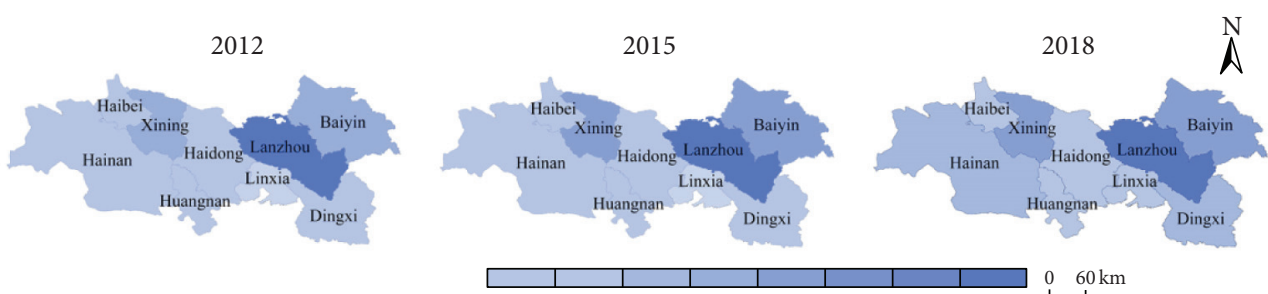

(f)

FIGURE 5: Spatial differentiation of the high-quality development level in Lanzhou-Xining urban agglomeration. 
TABLE 3: The high-quality development index of cities, 2012-2018.

\begin{tabular}{ccccccccccc}
\hline Year & Lanzhou & Baiyin & Dingxi & Linxia & Xining & Haidong & Hainan & Haibei & Huangnan & Coefficient of variation \\
\hline 2012 & 0.284 & 0.160 & 0.050 & 0.038 & 0.149 & 0.067 & 0.055 & 0.042 & 0.043 & 0.847 \\
2015 & 0.289 & 0.175 & 0.050 & 0.047 & 0.179 & 0.069 & 0.064 & 0.052 & 0.059 & 0.781 \\
2018 & 0.318 & 0.197 & 0.085 & 0.057 & 0.185 & 0.080 & 0.086 & 0.059 & 0.075 & 0.697 \\
\hline
\end{tabular}

TABLE 4: Correlation test between UCI and HDI in Lanzhou-Xining urban agglomeration.

\begin{tabular}{|c|c|c|c|c|c|c|c|c|c|c|c|c|c|c|c|c|}
\hline & \multirow{3}{*}{ Indexes } & \multicolumn{15}{|c|}{ High-quality development } \\
\hline & & \multicolumn{3}{|c|}{ Innovation development } & \multicolumn{3}{|c|}{ Coordination development } & \multicolumn{3}{|c|}{ Green development } & \multicolumn{3}{|c|}{ Openness development } & \multicolumn{3}{|c|}{ Sharing development } \\
\hline & & Al & A2 & A3 & B1 & B2 & B3 & $\mathrm{C} 1$ & $\mathrm{C} 2$ & $\mathrm{C} 3$ & D1 & D2 & D3 & E1 & E2 & E3 \\
\hline \multirow{4}{*}{ 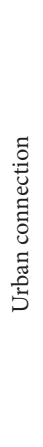 } & $\begin{array}{c}\text { Industrial } \\
\text { connection }\end{array}$ & & & & & & & & & & & & & & & \\
\hline & $\begin{array}{c}\text { Transportation } \\
\text { connection }\end{array}$ & & & & & & & & & & & & & & & \\
\hline & $\begin{array}{l}\text { Information } \\
\text { connection }\end{array}$ & & & & & & & & & & & & & & & \\
\hline & $\begin{array}{l}\text { Innovative } \\
\text { connection }\end{array}$ & & & & & & & & & & & & & & & \\
\hline
\end{tabular}

Notes: red color indicates significance at $1 \%$ level; green color indicates significance at $5 \%$ level; gray color indicates not significant.

Xining had a higher coordination degree. Baiyin, Dingxi, Linxia, and Haidong were in a state of mild disorder.

From 2012 to 2018, the degree of coupling and coordination between UCI and HDI of cities both increased; the values were $[0.38,0.44]$ and $[0.24,0.30]$, respectively, indicating that there is an antagonistic stage and a mild disorder between the external connection and urban high-quality development. The degree of coupling and coordination both increased, indicating that the degree of interaction and mutual influence between the two has deepened. In 2012, the general coordination areas included Lanzhou and Xining, while the severely imbalanced cities included Huangnan, Haibei, Hainan, and Linxia, and the mildly disordered cities included Baiyin, Dingxi, and Haidong. In 2018, only Huangnan and Haibei remained as the severely imbalanced cities, and the number of mildly disordered areas increased. The coordination degree between UCI and HDI of Lanzhou and Xining has always been high.

\section{Discussion}

5.1. Research Implications. The concept of high-quality development put forward by the Chinese government is consistent with the UN's 2030 Sustainable Development Goals (SDGs), representing the concrete implementation way of the SDGs in China [56]. It emphasizes both the speed and the quality of development, regards the people-oriented concept, and balances efficiency and equity. The evaluation system of urban high-quality development proposed in this
TABLE 5: Regression results of HDI and four UCIs.

\begin{tabular}{lc}
\hline Variable & Coefficient estimates \\
\hline $\ln I C$ & $0.317^{*}(0.172)$ \\
$\operatorname{lnTC}$ & $0.159^{* *}(0.072)$ \\
$\operatorname{lnNC}$ & $0.013(0.021)$ \\
$\operatorname{lnINC}$ & $0.023(0.017)$ \\
Constant & $-4.989^{* * *}(1.072)$ \\
R-squared & 0.876 \\
City FE & Yes \\
Year FE & No \\
Number of observations & 27 \\
\hline
\end{tabular}

Note: $^{* * *},{ }^{* *}$, and ${ }^{*}$ indicate significant correlation at $1 \%, 5 \%$, and $10 \%$ confidence level. The numbers in parentheses indicate the standard error.

paper may be a reference for studying other countries or regions.

Most previous studies have focused on urban connections or urban networks only considering individual aspects, such as knowledge collaboration [49, 57], traffic flow $[46,58]$, and network connection [59]. The UCI established in this study synthesized these dimensions. Considering the actual situation of the case, related methods have been improved. For example, we added the number of passenger buses in the transportation connection model to improve the accuracy; when constructing the information connection model, network big data were used to reflect the intensity of information flow between cities. This study provides a methodological reference for future research. 


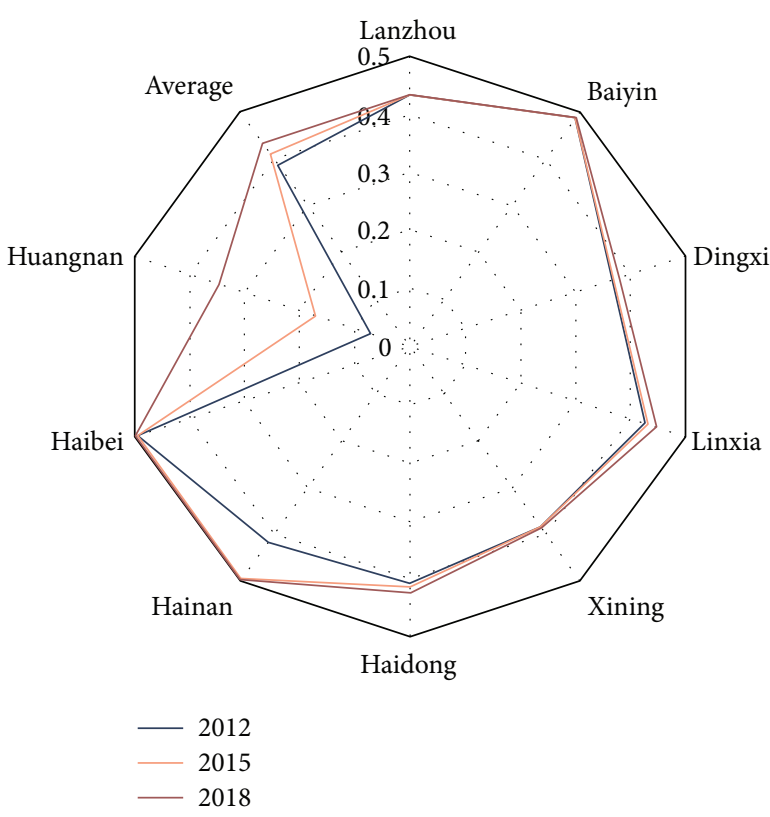

(a)

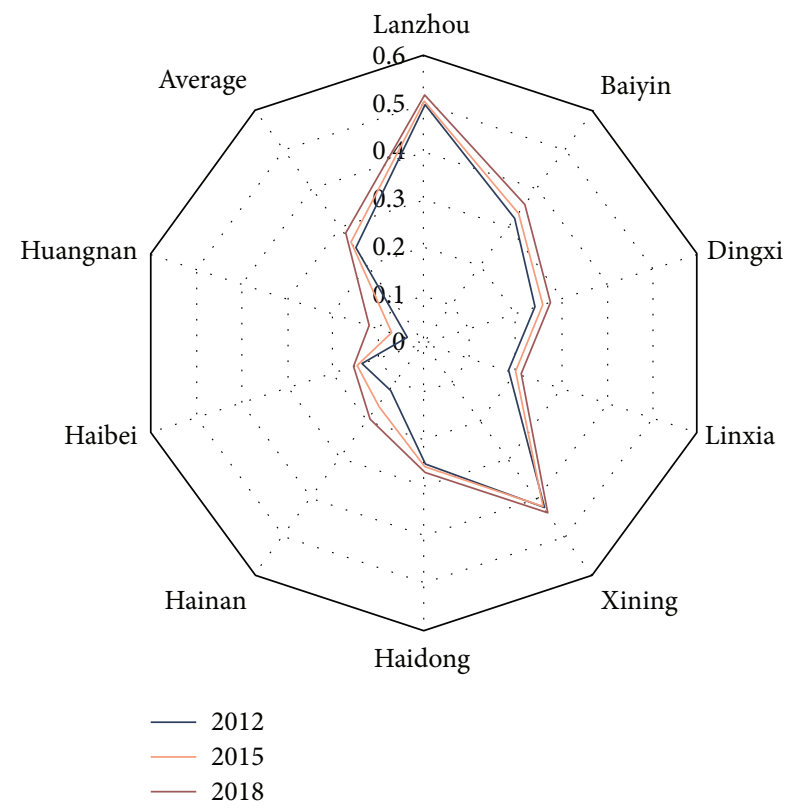

(b)

FIgURE 6: The degree of coupling and coordination between UCI and HDI in Lanzhou-Xining urban agglomeration. (a) Coupling degree and (b) coordination degree.

5.2. Policy Implications. This study proved that the cities' external connections have positive effects on urban development by quantitative analysis, providing a decision-making reference for other regions or countries. The multicenter and network of urban agglomerations help to achieve balanced and high-quality regional development. For industrial connections, it is important to further clarify the industrial function positioning of different cities so as to promote functional complementarity. Cities should develop in complementarity, barriers to the flow of elements should be broken, and an industrial chain cycle should be formed. For transportation connections, the traffic lines between major cities and key towns should be strengthened; the integrated ticket connection between different modes of transportation and the one-card interoperability should be promoted. For information connection, many measures can effectively promote network connections between cities such as improving the layout of high-speed information networks, accelerating the construction of $5 \mathrm{G}$ networks, and promoting the integration of e-government platforms. For innovative connection, cities should improve the market mechanism to transform scientific and technological achievements and promote the in-depth integration of production, education, and research of innovation subjects.

5.3. Research Shortcoming and Prospects. The present study only considered four dimensions of industry, transportation, information, and innovation in the urban connection. In the future, it is necessary to improve the evaluation index system and supplement the city's connection in the dimensions of politics and culture. Whether the relationship between UCI and HDI demonstrated in Lanzhou-Xining urban agglomeration is a universal need to be tested by further using other regions as examples. The interaction mechanism and quantitative relationship between urban connections and high-quality development need to be further explored by applying complexity science.

\section{Conclusions}

This study contributes to the scientific community in two points. The UCI and HDI were constructed from multiple dimensions based on big data and statistical data, and the coupling relationship between UCI and HDI was determined. The main findings are as follows.

From 2012 to 2018, the UCI of each city in LanzhouXining urban agglomeration showed different degrees of growth. The fastest growing cities were Huangnan and Haibei. Lanzhou and Xining had the highest connection intensity in all dimensions. Urban high-quality development can be measured through five dimensions: innovation, coordination, green development, openness, and sharing. The overall high-quality development level of each city was on the rise, but there were regional differences. Lanzhou and Xining had the highest level of HDI, but the other cities were far behind. The biggest gap was in the innovation development level, and the gap in green and sharing development was small.

UCIs are significantly correlated with most indexes of high-quality development, especially innovative and green development. This means that the enhancement of the external connections and openness of an urban system is likely to facilitate high-quality development. Analysis of our case shows that, for every $1 \%$ increase in industrial and transportation connection, the urban high-quality development 
level will increase by $0.317 \%$ and $0.159 \%$, while the influence of information and innovative connection is not significant. There is an antagonistic relation and a mild disorder between the UCI and HDI of the cities, but the trend is improving.

\section{Data Availability}

All input data used in these analyses were derived from published sources cited within the article. Any other datasets generated in the current study are available from the corresponding author upon request.

\section{Conflicts of Interest}

The authors declare no conflicts of interest.

\section{Acknowledgments}

This research was funded by the National Natural Science Foundation of China (Grant no. 41771130) and the Research Funding for the Second Comprehensive Scientific Investigation of the Qinghai-Tibet Plateau (Grant no. 2019QZKK1005).

\section{References}

[1] H. H. Shih-Kung Lai, Urban Complexity and Planning: Theories and Computer Simulations, Taylor and Francis, Milton Park, Abingdon, UK, 2016.

[2] Y. J. Shi, G. F. Zhai, L. H. Xu et al., "Assessment methods of urban system resilience: from the perspective of complex adaptive system theory," Cities, vol. 112, p. 13, 2021.

[3] M. Batty, "The size, scale, and shape of cities," Science, vol. 319, no. 5864, pp. 769-771, 2008.

[4] X. Cui, C. Fang, H. Liu, and X. Liu, "Assessing sustainability of urbanization by a coordinated development index for an urbanization-resources-environment complex system: a case study of Jing-Jin-Ji region, China," Ecological Indicators, vol. 96, pp. 383-391, 2019.

[5] M. J. Burger and E. J. Meijers, "Agglomerations and the rise of urban network externalities," Papers in Regional Science, vol. 95, no. 1, pp. 5-15, 2016.

[6] H. Xin, "Jinping Xi on China's high-quality development," 2021.

[7] C. Fang, "Progress and the future direction of research into urban agglomeration in China," Acta Geographica Sinica, vol. 69, no. 8, pp. 1130-1144, 2014.

[8] T. B. Levent, S. Kundak, and A. A. Gulumser, "City-to-city linkages in a mobile society: the role of urban networks in Eurocities and Sister Cities," International Journal of Services Technology and Management, vol. 10, no. 1, pp. 83-109, 2008.

[9] B. Blondé, "At the cradle of the transport revolution?" The Journal of Transport History, vol. 31, no. 1, pp. 89-111, 2010.

[10] W. Zheng, A. Kuang, X. Wang, and J. Chen, "Measuring network configuration of the Yangtze river middle reaches urban agglomeration: based on modified radiation model," Chinese Geographical Science, vol. 30, no. 4, pp. 677-694, 2020.

[11] T. Wang, W. Yue, X. Ye, Y. Liu, and D. Lu, "Re-evaluating polycentric urban structure: a functional linkage perspective," Cities, vol. 101, 2020.

[12] H. Yang, M. Dijst, P. Witte, H. van Ginkel, and J. E. Wang, "Comparing passenger flow and time schedule data to analyse high-speed railways and urban networks in China," Urban Studies, vol. 56, no. 6, pp. 1267-1287, 2019.

[13] S. Hallegatte, "Storm damages and inter-city trade," Nature Sustainability, vol. 3, no. 8, pp. 577-578, 2020.

[14] D. Li, Y. D. Wei, and T. Wang, "Spatial and temporal evolution of urban innovation network in China," Habitat International, vol. 49, pp. 484-496, 2015.

[15] P. Hall, The Polycentric Metropolis: A Western European Perspective on Mega-City Regions, Governance and Planning of Mega-City Regions, Routledge, Milton Park, Abingdon, UK, 2010.

[16] C. L. Fang, X. H. Yu, X. L. Zhang, J. W. Fang, and H. M. Liu, "Big data analysis on the spatial networks of urban agglomeration," Cities, vol. 102, p. 16, 2020.

[17] H. Tong, P. Shi, J. Luo, and X. Liu, "The structure and pattern of urban network in the Lanzhou-Xining urban agglomeration," Chinese Geographical Science, vol. 30, no. 1, pp. 59-74, 2020.

[18] R. Capello, "The city network paradigm: measuring urban network externalities," Urban Studies, vol. 37, no. 11, pp. 1925-1945, 2000.

[19] L. Wang, W. Xiao, and C. Wang, "Evolution of hierarchical structure and spatial pattern of coastal cities in China-based on the data of distribution of marine-related enterprises," Polish Maritime Research, vol. 24, no. s3, pp. 58-64, 2017.

[20] Y. Chen, "Urban gravity model based on cross-correlation function and Fourier analyses of spatio-temporal process," Chaos, Solitons \& Fractals, vol. 41, no. 2, 2008.

[21] Y. Zhao, G. Zhang, and H. Zhao, "Spatial network structures of urban agglomeration based on the improved gravity model: a case study in China's two urban agglomerations," Complexity, vol. 2021, Article ID 6651444, 17 pages, 2021.

[22] X. Jin, G. Hu, H. Ding, S. Ye, Y. Lu, and J. Lin, "Evolution of spatial structure patterns of city networks in the Yangtze River Economic Belt from the perspective of corporate pledge linkage," Growth and Change, vol. 51, no. 2, 2020.

[23] L. Zhang and Y. Lu, "Regional accessibility of land traffic network in the Yangtze River Delta," Journal of Geographical Sciences, vol. 17, no. 3, pp. 351-364, 2007.

[24] C. Gan, M. Voda, K. Wang, L. Chen, and J. Ye, "Spatial network structure of the tourism economy in urban agglomeration: a social network analysis," Journal of Hospitality and Tourism Management, vol. 47, pp. 124-133, 2021.

[25] X. Cao, G. Zeng, L. Lin, and L. Zou, "Hierarchical characteristics and proximity mechanism of intercity innovation networks: a case of 290 cities in China," Complexity, vol. 2021, Article ID 5538872, 14 pages, 2021

[26] Y. Lichi, "Evaluation of urban development quality based on the connotation of high-quality development: a case study of guangdong province," Journal of Landscape Research, vol. 11, no. 2, pp. 83-89, 2019.

[27] L. Chen, W. Ye, C. Huo, and K. James, "Environmental regulations, the industrial structure, and high-quality regional economic development: evidence from China," Land, vol. 9, no. 12 , p. $517,2020$.

[28] J. Long, Z. Qiting, M. Junxia, and Z. Zhizhuo, "Evaluation and prediction of the level of high-quality development: a case study of the Yellow River Basin, China," Ecological Indicators, vol. 129, 2021.

[29] A. Jahanger, "Influence of FDI characteristics on high-quality development of China's economy," Environmental Science and Pollution Research, vol. 28, no. 15, pp. 18977-18988, 2021. 
[30] A. Huerta-Barrientos, Scaling in Urban Complex Systems: Mexico City Metabolism, Intech Open Science, London, UK, 2018.

[31] H. M. Liu, C. L. Fang, and Q. Gao, "Evaluating the real-time impact of COVID-19 on cities: China as a case study," Complexity, vol. 2020, Article ID 8855521, 11 pages, 2020.

[32] L. Inostroza and H. Zepp, "The metabolic urban network: urbanisation as hierarchically ordered space of flows," Cities, vol. 109, 2021.

[33] K. Mainzer and R. Landauer, "Thinking in complexity: the complex dynamics of matter, mind, and mankind," American Journal of Physics, vol. 63, no. 8, 1995.

[34] H. Liu, C. Fang, and K. Fang, "Coupled Human and Natural Cube: a novel framework for analyzing the multiple interactions between humans and nature," Journal of Geographical Sciences, vol. 30, no. 3, pp. 355-377, 2020.

[35] L. M. A. Bettencourt, "The origins of scaling in cities," Science, vol. 340, no. 6139, pp. 1438-1441, 2013.

[36] M. Castells, "Space of flows, space of places: materials for a theory of urbanism in the information age," The City Reader, pp. 263-274, Routledge, Milton, UK, 2015.

[37] A. Bassolas, H. Barbosa-Filho, B. Dickinson et al., "Hierarchical organization of urban mobility and its connection with city livability," Nature Communications, vol. 10, no. 1, p. 4817, 2019.

[38] Y. Wei, W. Song, C. Xiu, and Z. Zhao, "The rich-club phenomenon of China's population flow network during the country's spring festival," Applied Geography, vol. 96, pp. 77-85, 2018.

[39] W. Zhang, B. Derudder, J. Wang, and F. Witlox, "An analysis of the determinants of the multiplex urban networks in the Yangtze river delta," Tijdschrift voor Economische en Sociale Geografie, vol. 111, no. 2, pp. 117-133, 2020.

[40] P. J. Taylor, "Leading world cities: empirical evaluations of urban nodes in multiple networks," Urban Studies, vol. 42, no. 9, pp. 1593-1608, 2005.

[41] B. Trinh and K. Kobayashi, "Measuring the effective rate of protection in Vietnam's economy with emphasis on the manufacturing industry: an input-output approach," 2010.

[42] L. Lai, X. Huang, and W. Liu, "Adjustment for regional ecological footprint based on input-output technique: a case study of Jiangsu Province in 2002," Acta Ecologica Sinica, vol. 26, no. 4, pp. 1285-1292, 2006.

[43] L. Xie, Q. Xue, and Z. Yuan, "Composition and spatial difference of agro-industry carbon footprint in Hebei province, North China," Ecological Indicators, vol. 97, pp. 141-149, 2019.

[44] G. H. M. Sonis, Fields of Influence and Extended Input-Output Analysis: A Theoretical Account, Avebury, Aldershot, UK, 1991.

[45] M. Sonis and G. J. D. Hewings, "Economic complexity as network complication: multiregional input-output structural path analysis," The Annals of Regional Science, vol. 32, no. 3, pp. 407-436, 1998.

[46] F. Zhang, Y. Ning, and X. Lou, "The evolutionary mechanism of China's urban network from 1997 to 2015: an analysis of air passenger flows," Cities, vol. 109, 2021.

[47] K. Liu, T. Wang, Z. Yang et al., "Using Baidu search index to predict dengue outbreak in China," Scientific Reports, vol. 6, no. 1, pp. 38040-38049, 2016.

[48] Z. Zhang and W. Tang, "Analysis of spatial patterns of public attention on housing prices in Chinese cities: a web search engine approach," Applied Geography, vol. 70, 2016.

[49] Y. Li and N. A. Phelps, "Megalopolis unbound: knowledge collaboration and functional polycentricity within and beyond the Yangtze River Delta Region in China," Urban Studies, vol. 55, pp. 433-460, 2014.

[50] Q. Wang, R. Han, Q. Huang et al., "Research on energy conservation and emissions reduction based on AHP-fuzzy synthetic evaluation model: a case study of tobacco enterprises," Journal of Cleaner Production, vol. 201, pp. 88-97, 2018.

[51] S. Mei, H. Xuguang, Z. Liyan et al., "Transformation performance and subsystem coupling of resource-based cities in China: an analysis based on the support-pressure framework," Integrated Environmental Assessment and Management, pp. 1-14, 2021.

[52] B. Zhu, M. Zhang, Y. Zhou et al., "Exploring the effect of industrial structure adjustment on interprovincial green development efficiency in China: A novel integrated approach," Energy Policy, vol. 134, Article ID 110946, 2019.

[53] L. Ran, X. D. Tan, Y. Xu et al., "The application of subjective and objective method in the evaluation of healthy cities: a case study in Central China," Sustainable Cities and Society, vol. $65,2021$.

[54] D. Luo, L. W. Liang, Z. B. Wang, L. K. Chen, and F. M. Zhang, "Exploration of coupling effects in the economy-society-environment system in urban areas: case study of the Yangtze river delta urban agglomeration," Ecological Indicators, vol. 128, 2021.

[55] L. Ding, W. Zhao, Y. Huang, S. Cheng, and C. Liu, "Research on the coupling coordination relationship between urbanization and the air environment: a case study of the area of Wuhan," Atmosphere, vol. 6, no. 10, 2015.

[56] Y. Cheng, H. Liu, S. Wang, X. Cui, and Q. Li, "Global action on SDGs: policy review and outlook in a post-pandemic era," Sustainability, vol. 13, no. 11, 2021.

[57] Z. Ba, Y. Ma, and Z. Liang, "Exploring the effect of city-level collaboration and knowledge networks on innovation: evidence from energy conservation field," Journal of Informetrics, vol. 15, no. 3, 2021.

[58] X. Yang, R. Wang, D. Guo, and W. Sun, "The reconfiguration effect of China's high-speed railway on intercity connection-a study based on media attention index," Transport Policy, vol. 95, pp. 47-56, 2020.

[59] H. Wang, W. Wang, Y. Meng, and Y. Zhang, "Degree of user attention to a webpage based on Baidu index: an alternative to page view," Journal of Experimental \& Theoretical Artificial Intelligence, vol. 26, no. 2, 2014. 